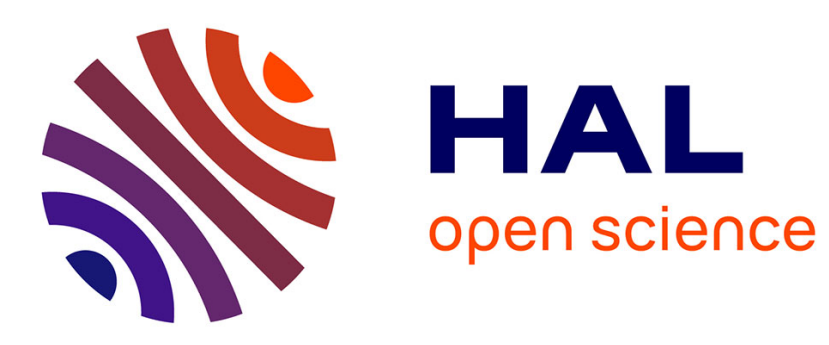

\title{
Quantitative analysis of electronic absorption of phosphorus donors in diamond
}

I. Stenger, Marie-Amandine Pinault-Thaury, Alain Lusson, Thierry

Kociniewski, François Jomard, Jacques Chevallier, Julien Barjon

\section{- To cite this version:}

I. Stenger, Marie-Amandine Pinault-Thaury, Alain Lusson, Thierry Kociniewski, François Jomard, et al.. Quantitative analysis of electronic absorption of phosphorus donors in diamond. Diamond and Related Materials, 2017, 74, pp.24-30. 10.1016/j.diamond.2017.01.012 . hal-02440909

\section{HAL Id: hal-02440909 \\ https://hal.science/hal-02440909}

Submitted on 27 Jan 2021

HAL is a multi-disciplinary open access archive for the deposit and dissemination of scientific research documents, whether they are published or not. The documents may come from teaching and research institutions in France or abroad, or from public or private research centers.
L'archive ouverte pluridisciplinaire HAL, est destinée au dépôt et à la diffusion de documents scientifiques de niveau recherche, publiés ou non, émanant des établissements d'enseignement et de recherche français ou étrangers, des laboratoires publics ou privés. 
1 Quantitative analysis of electronic absorption of phosphorus donors in

2 diamond

3

4

\section{5}

6
I. Stenger, M.-A. Pinault-Thaury, A. Lusson, T. Kociniewski, F. Jomard, J. Chevallier and J. Barjon

Université Paris Saclay, Université St Quentin Yvelines, CNRS, GEMaC

45 avenue des Etats Unis, 78035 Versailles Cedex, France

*corresponding author

+33(0)13925 4671 / (ingrid.stenger@uvsq.fr, I. Stenger)

\section{ABSTRACT}

In this work, phosphorus donors in diamond have been investigated by means of Fourier Transform Infra-Red (FTIR) transmission spectroscopy on a series of fully-characterized homoepitaxial layers. Low-temperature FTIR absorption spectra have been obtained for concentrations of donors in the range $\mathrm{N}_{\mathrm{D}}=3.7 \times 10^{16}-3.5 \times 10^{18} \mathrm{~cm}^{-3}$ and compensating acceptor impurities in the range $\mathrm{N}_{\mathrm{A}}=2.3 \times 10^{16}-3.0 \times 10^{18} \mathrm{~cm}^{-3}$. The absorption spectra is shown to exhibit two peaks at $4220 \mathrm{~cm}^{-1}$ and $4540 \mathrm{~cm}^{-1}$ corresponding to electronic transitions from the ground state to the $2 \mathrm{p}_{0}$ and $2 \mathrm{p}_{+/-}$excited states, respectively, of phosphorus donors in the neutral state of charge. The intensity of the most intense peak at $4540 \mathrm{~cm}^{-1}$ is found proportional to $\mathrm{N}_{\mathrm{D}}-\mathrm{N}_{\mathrm{A}}$ over two decades. The absorption cross-section of the corresponding transition is deduced providing a calibration law for the determination of $\mathrm{N}_{\mathrm{D}}-\mathrm{N}_{\mathrm{A}}$ in phosphorusdoped diamond. Furthermore, the linewidth of the peak exhibits a linear variation with the compensating acceptor concentration, interpreted as the effect of the distribution of ionized impurities. The use of the non-destructive and contact-less FTIR optical method is finally discussed to determine the compensation ratio in phosphorus-doped diamond.

Keywords : Infrared absorption, n-type diamond, diamond impurities, wide bandgap semiconductor 
The n-type conductivity in diamond is presently one of the major issues for electronic applications such as high power devices, UV light emitting diodes, DNA sensors, and electron emitters $[1,2,3,4,5,6]$. Up to now phosphorus is the substitutional donor which gives the highest n-type conductivities, despite its high ionization energy of $0.6 \mathrm{eV}$ [7]. Using microwave-

6 plasma-assisted chemical vapour deposition (MPCVD), phosphorus can be incorporated in substitutional sites of the diamond lattice during the growth. Its incorporation remains easier on (111) oriented diamond surfaces than on $(100)[8,9]$ though this surface is preferred for applications. However, both (111) and (100) homoepitaxial layers still suffer from a relatively high compensation of donors by residual impurities and defects [10]. Today, it is striking that the n-type conductivity of phosphorus-doped diamond at room temperature is mainly limited by the problem of compensation rather than by the donor concentration. Up to now, the lowest compensation ratios, defined as $\mathrm{k}=\mathrm{N}_{\mathrm{A}} / \mathrm{N}_{\mathrm{D}},\left(\mathrm{N}_{\mathrm{A}}\right.$ the compensating acceptor concentration and $\mathrm{N}_{\mathrm{D}}$ the donor concentration) reported in n-type diamond are $\sim 40 \%$ on the (100) orientation [11] and $\sim 5 \%$ on the (111) orientation [12], as deduced from electrical measurements. The contrast

16 is striking with p-type diamond doped with boron where the compensation ratio can reach values below one part per million [13].

Evaluating the compensation ratio of phosphorus-doped diamond by Hall effect measurements is not an easy task because of the high resistivity of the films and the high contact resistance of metals on n-type diamond. Cathodoluminescence (CL) spectroscopy has proven

21 [14] to be a powerful optical technique to quantify the concentration of phosphorus incorporated 22 in donor sites, $\mathrm{N}_{\mathrm{D}}$. However, under electron-hole pair injection, all acceptors are neutralized. 23 Consequently, the compensation effect is not assessed with CL spectroscopy. 
An alternative technique to probe the phosphorus donors in diamond is infrared absorption spectroscopy. It is commonly used for a quantitative analysis of impurity concentrations in semiconductors from the knowledge of the absorption cross-section of electronic or vibrational transitions [15]. For p-type diamond doped with boron, Collins et al correlated the absorption intensity of the electronic transitions of neutral boron to its concentration and provided calibration curves [16]. In 2000, electronic transitions between the ground state $1 \mathrm{~s}$ and different excited states of neutral phosphorus atoms were observed by infrared absorption spectroscopy by Gheeraert et al. The authors discussed the photoionization background and related its magnitude to the phosphorus content in the gas mixture during growth [17]. However, the lack of accurate values of $\mathrm{N}_{D}$ and $\mathrm{N}_{\mathrm{A}}$ in their samples prevent them to give a more useful calibration law for phosphorus-doped diamond characterization. it is the most intense absorption line associated to the electronic transitions of phosphorus donors in diamond. The infrared absorption measurements have been performed in a series of extensively characterized homoepitaxial layers with different phosphorus doping levels. We demonstrate that the intensity of the electronic absorption of phosphorus donors at $4540 \mathrm{~cm}^{-1}$ is proportional to the net donor density, namely $\mathrm{N}_{\mathrm{D}}-\mathrm{N}_{\mathrm{A}}$. We provide a calibration curve for the measurement of $\mathrm{N}_{\mathrm{D}}-\mathrm{N}_{\mathrm{A}}$ by using infrared spectroscopy. We also observe that the linewidth of the $1 \mathrm{~s} \rightarrow 2 \mathrm{p}_{ \pm}$absorption peak follows a linear dependency on $\mathrm{N}_{\mathrm{A}}$. The possible origins of the broadening are discussed. We further evaluate the uncertainty associated to the determination

21 of the compensation from infrared measurements, performed alone or in a combination with other techniques, such as CL or Secondary Ion Mass Spectrometry (SIMS). 
2 The (111) and (100) phosphorus doped homoepitaxial diamond films were grown on type $\mathrm{Ib}$

3 diamond crystals by microwave plasma assisted chemical vapor deposition (MPCVD). For the

4 (111) orientation, the deposition conditions were described by Kociniewski et al [18, 19]. The

5 D147 and D166 samples are replicas of the D42 sample, with $\mathrm{N}_{\mathrm{D}}$ of the same order of

6 magnitude. The (100) oriented sample was grown thanks to the new set of growth parameters

7 we found recently [20].

Secondary-ion mass spectrometry experiments (SIMS) using a Cameca IMS 4f

9 equipment were performed onto the samples in order to measure the depth distribution of $\mathrm{P}, \mathrm{B}$,

$10 \mathrm{~N}, \mathrm{H}$ atoms into the diamond films, with $\mathrm{Cs}^{+}$primary ions accelerated at $10 \mathrm{keV}$. In most of the

11 samples, a single SIMS crater of approximately $150 \mathrm{x} 150 \mu \mathrm{m}^{2}$ was dug at sample edges $\left(2 \times 2 \mathrm{~mm}^{2}\right.$ or

$123 \times 3 \mathrm{~mm}^{2}$ ). The concentrations of $\mathrm{P}$ and $\mathrm{B}$ were quantified by using implanted standards. As

13 shown in our previous papers, the phosphorus concentration of our epilayers is quite

14 homogeneous both in depth and laterally [19]. Nevertheless, for each sample, we present the

15 mean value of the SIMS profile on the whole layer thickness. The hydrogen and nitrogen

16 concentrations are at the SIMS level detection limit while the residual boron concentration

17 (contamination) is in the range $1.5-6 \times 10^{16} \mathrm{~cm}^{-3}$, well below the $\mathrm{P}$ concentration. The $\mathrm{P}$

18 concentration ranged from $3.7 \times 10^{16}$ at. $\mathrm{cm}^{-3}$ to $3.5 \times 10^{18}$ at. $\mathrm{cm}^{-3}$ and the thickness of the epilayers

19 ranged from 1 to $6.3 \mu \mathrm{m}$. The relative uncertainties are estimated at $10 \%$ both for the $\mathrm{P}$

20 concentration and the film thickness.

The DC electrical measurements were performed by resistivity and Hall effect in a van der Pauw configuration from $300 \mathrm{~K}$ to $900 \mathrm{~K}$ under a DC magnetic field of $0.8 \mathrm{~T}$, with a high impedance setup. The Hall scattering factor is assumed to be equal to 1 . Prior to the electrical 
1 measurements, the as-grown diamond film surfaces were oxidized in order to remove the

2 surface conductive layer due to the hydrogen termination (see ref. [18] for details). determine the neutral donor concentration profile $\mathrm{N}_{\mathrm{D}}-\mathrm{N}_{\mathrm{A}}$ in the first $500 \mathrm{~nm}$ of the film (see ref [11] for details), with a relative uncertainty estimated at $10 \%$. Fourier Transform Infrared interferometer. Liquid nitrogen or liquid helium were used to cool down the samples at temperatures ranging from $10 \mathrm{~K}$ to $250 \mathrm{~K}$. A globar light source and a InSb detector were used. The spectral resolution was set to $4 \mathrm{~cm}^{-1}$. The transmission was normalized to $\mathrm{T} / \mathrm{T}_{0}=1$ at $4000 \mathrm{~cm}^{-1}$ where the absorption of neutral phosphorus vanishes $(\mathrm{T}$ : sample transmission and $\mathrm{T}_{0}$ : sample transmission at $4000 \mathrm{~cm}^{-1}$ ). The absorption coefficient was

12 then found from the usual relationship: $\alpha=-\frac{1}{d} \ln \left(\frac{T}{T_{0}}\right)$, $d$ being the film thickness obtained from SIMS analysis.

\section{RESULTS AND DISCUSSION}

\section{A. Compensation ratio and neutral donor concentration}

As a result of the almost complete substitutional incorporation of phosphorus in (111) epilayers [21] and also in the (100) epilayer we have investigated [20], we consider that all phosphorus atoms incorporated in diamond in the series of samples act as donors. In other words, phosphorus are located in substitution of carbon atoms and are not complexed with other impurity or defects (ex : $\mathrm{H}$ or $\mathrm{V}$ ). Consequently, we will assume that the phosphorus concentration deduced from SIMS experiments equals the concentration of donors $\left(\mathrm{N}_{\mathrm{D}}\right)$.

From Hall effect measurements as a function of temperature, we deduce the compensation ratio $\mathrm{k}=\mathrm{N}_{\mathrm{A}} / \mathrm{N}_{\mathrm{D}}$ for the (111) oriented samples by using the procedure described in ref. [22]. The equivalent density of states effective mass was updated to $m_{c}^{*}=1.639 \mathrm{~m}_{0}$ 
1 following the work of Naka et al. [23]. It follows a slightly different value of k comparing to

2 those found in ref. 22. The relative uncertainty is estimated at $\Delta \mathrm{k} / \mathrm{k}=20 \%$. For the (100) oriented

3 sample D169b, the compensation ratio was determined by combining : (i) the neutral donor

4 concentration $\mathrm{N}_{\mathrm{D}}-\mathrm{N}_{\mathrm{A}}$ extracted from $\mathrm{C}(\mathrm{V})$ measurements on the first $500 \mathrm{~nm}$ of the film ${ }^{1}$ and

5 (ii) the donor concentration $\mathrm{N}_{\mathrm{D}}$ measured by SIMS on the same part of the film. We then

6 assumed that $\mathrm{k}$ is constant in the entire thickness of the film. The sample characteristics are

7 summarized in Table $\mathrm{I}^{2}$.

8 TABLE I. Sample characteristics. Phosphorus donor concentrations $\left(\mathrm{N}_{\mathrm{D}}\right)$ from SIMS, thickness

9 (d), compensation ratio $(\mathrm{k})$ deduced from electrical measurements and the corresponding

10 concentrations of compensating acceptors $\left(\mathrm{N}_{\mathrm{A}}\right)$ and neutral phosphorus donors $\left(\mathrm{N}_{\mathrm{D}}-\mathrm{N}_{\mathrm{A}}=(1-\right.$

$11 \mathrm{k}) \mathrm{N}_{\mathrm{D}}$ ), integrated intensity $\left(\mathrm{I}_{\mathrm{A}}\right)$ and full width at half maximum $(\Gamma)$ of the $1 \mathrm{~s} \rightarrow 2 \mathrm{p}_{ \pm}$absorption

12 peak. Sample D169b is (100)-oriented. All others are (111)-oriented.

\begin{tabular}{|l|l|l|l|l|l|l|l|}
\hline $\begin{array}{l}\text { Sample } \\
\text { ref. }\end{array}$ & $\mathrm{N}_{\mathrm{D}}\left(\mathrm{cm}^{-3}\right)$ & $\mathrm{d}(\mu \mathrm{m})$ & $\mathrm{k}(\%)$ & $\mathrm{N}_{\mathrm{A}}\left(\mathrm{cm}^{-3}\right)$ & $\mathrm{N}_{\mathrm{D}}-\mathrm{N}_{\mathrm{A}}\left(\mathrm{cm}^{-3}\right)$ & $\mathrm{I}_{\mathrm{A}}\left(\mathrm{cm}^{-2}\right)$ & $\Gamma\left(\mathrm{cm}^{-1}\right)$ \\
\hline D169b & $3.7 \times 10^{16}$ & 6.30 & 40 & $1.5 \times 10^{16}$ & $2.3 \times 10^{16}$ & 75 & 15 \\
\hline $\mathrm{D} 46$ & $6 \times 10^{17}$ & 1.32 & 34 & $2.0 \times 10^{17}$ & $4.0 \times 10^{17}$ & 1777 & 25 \\
\hline D43 & $8.5 \times 10^{17}$ & 1.62 & 34 & $2.9 \times 10^{17}$ & $5.6 \times 10^{17}$ & 3031 & 31 \\
\hline D48 & $9.4 \times 10^{17}$ & 1.46 & 14 & $1.3 \times 10^{17}$ & $8.1 \times 10^{17}$ & 2668 & 23 \\
\hline D42 & $1.7 \times 10^{18}$ & 1.23 & 9 & $1.5 \times 10^{17}$ & $1.5 \times 10^{18}$ & 5160 & 26 \\
\hline D31 & $3.0 \times 10^{18}$ & 1.50 & 35 & $1.1 \times 10^{18}$ & $2.0 \times 10^{18}$ & -- & 64 \\
\hline D147 & $3.5 \times 10^{18}$ & 1.12 & 16 & $5.7 \times 10^{17}$ & $3.0 \times 10^{18}$ & 10403 & 44 \\
\hline D166 & $3.5 \times 10^{18}$ & 1.52 & 21 & $7.4 \times 10^{17}$ & $2.8 \times 10^{18}$ & 9500 & 39 \\
\hline
\end{tabular}

13

14 Let us discuss the origin of compensation in our n-type diamond layers. Residual boron

15 acceptors are naturally compensating centers. $[\mathrm{B}] \backslash[\mathrm{P}]$ is less than $3 \%$ in all the samples and is

\footnotetext{
${ }^{1}$ The achievement of ohmic contact is an issue in n-type diamond. At low doping, metallic layers usually gives rectifying-contact characteristics which impede Hall measurements. That's the reason why C(V) was used instead of Hall for the D169b sample which has the lightest doping.

${ }^{2}$ In the case of D169b which is a relatively thick layer, the phosphorus concentration varies along the layer (SIMS profile can be found in ref.20). The concentration given in ref [20] and [11] are averaged on the first $800 \mathrm{~nm}$ of the layer. This is the correct method to compare the impurity concentration with surfacic measurements such as a $\mathrm{C}(\mathrm{V})$ measurement or cathodoluminescence at low voltage. As FTIR absorption occurs in the whole film thickness, it is necessary to indicate the mean $\mathrm{N}_{\mathrm{D}}$ concentration over the total depth of the layer in table I.
} 
1 therefore much lower than $\mathrm{k}$. As a result, the compensation of phosphorus donors is not limited

2 by the presence of residual boron atoms in n-type diamond. Other residual impurities and/or defects reduce the phosphorus electrical activity. In high quality CVD diamond, the contamination with other elements $(\mathrm{N}, \mathrm{Si}, \ldots)$ would be almost negligible if enough care is taken in the growth process. $\mathrm{P}-\mathrm{H}$ and $\mathrm{P}-\mathrm{V}$ are possible compensating complexes in $\mathrm{n}$-type diamond $[24,25,26,27]$. However, they are expected to be in negligible concentration because $100 \%$ of the $\mathrm{P}$ atoms act as substitutional donors in our homoepitaxial layers. The hydrogenmulti vacancy complexes $\mathrm{V}_{\mathrm{n}}-\mathrm{H}_{\mathrm{n}}$ are other possible compensators of phosphorus donors. Some of them were identified and could act as compensators: H1, H2 [28], VH [29] and H1' [30]. The H1' center should be dominant in diamond epitaxy. Being often observed in undoped and

11 boron-doped CVD diamond by electron spin resonance (ESR) [28], this hydrogen-vacancy complex presents a carbon dangling bond near a hydrogen atom. Note that extended defects specific to growth (e.g. dislocations) could also participate to the compensation of phosphorus donors. As a summary, the identification of compensating defects in phosphorus doped diamond remains an issue to be solved.

\section{B. Electronic transitions of neutral phosphorus donors in diamond}

A transmission spectrum at $10 \mathrm{~K}$ of a $3.5 \times 10^{18}$ at.cm ${ }^{-3}$ P-doped film (sample D147) is plotted in figure 1(a). From $1800 \mathrm{~cm}^{-1}$ to $4000 \mathrm{~cm}^{-1}$, it exhibits typical features corresponding to intrinsic absorption from diamond involving 2-phonons and 3-phonons lattice absorption bands [31]. At approximately $2800 \mathrm{~cm}^{-1}$, peaks associated to $\mathrm{C}-\mathrm{H}$ vibrations could be classically observed, as well as $\mathrm{H}_{2} \mathrm{O}$ artifacts at $3000 \mathrm{~cm}^{-1}$. The box presents a magnification of the 4000 $\mathrm{cm}^{-1}-5000 \mathrm{~cm}^{-1}$ spectral range in which the signature of electronic transitions of neutral phosphorus donors are expected.

The absorption coefficient at $10 \mathrm{~K}$ of sample D147 is plotted in figure 1(b). It exhibits a continuous background due to the photoionization continuum and two peaks attributed to the 
1 transitions from the ground level $1 \mathrm{~s}$ to the $2 \mathrm{p}_{0}$ and $2 \mathrm{p}_{ \pm}$excited states respectively at $4220 \mathrm{~cm}^{-1}$

$2(523 \mathrm{meV})$ and $4540 \mathrm{~cm}^{-1}(562 \mathrm{meV})$. Interestingly, Gheeraert et al. compared the positions of

3 the peaks to the results of the Effective Mass Approximation (EMA) [32]. While the excited

4 state energies of the phosphorus donor in diamond are well described in the EMA theory, it

5 fails to describe the ground state energy. The experimental ionization energy of phosphorus is

$6 \quad 0.6 \mathrm{eV}$ to be compared with $0.19 \mathrm{eV}$ for a hydrogenic donor in diamond. (This last value was

7 updated with the effective masses of ref [23] using the EMA theory described in details in ref

8 [33]). Such a discrepancy indicates that the wave function of the weakly bound electron of the

9 donor in its ground state is much strongly localized in the real space than predicted with the

10 EMA theory. Butorac et al. have indeed calculated the charge density along a P-C bond from

11 the density functional theory [34]. Their work shows that the phosphorus extra electron is

12 strongly localized around the phosphorus : the maximum of the charge density is found at only

$131.4 \stackrel{\circ}{\mathrm{A}}$ between phosphorus and its four nearest carbon neighbors. In the discussion of Part D,

14 we will use this value as an effective Bohr radius $\mathrm{a}^{*}=1.4 \stackrel{\circ}{\mathrm{A}}$ for phosphorus donors in diamond.
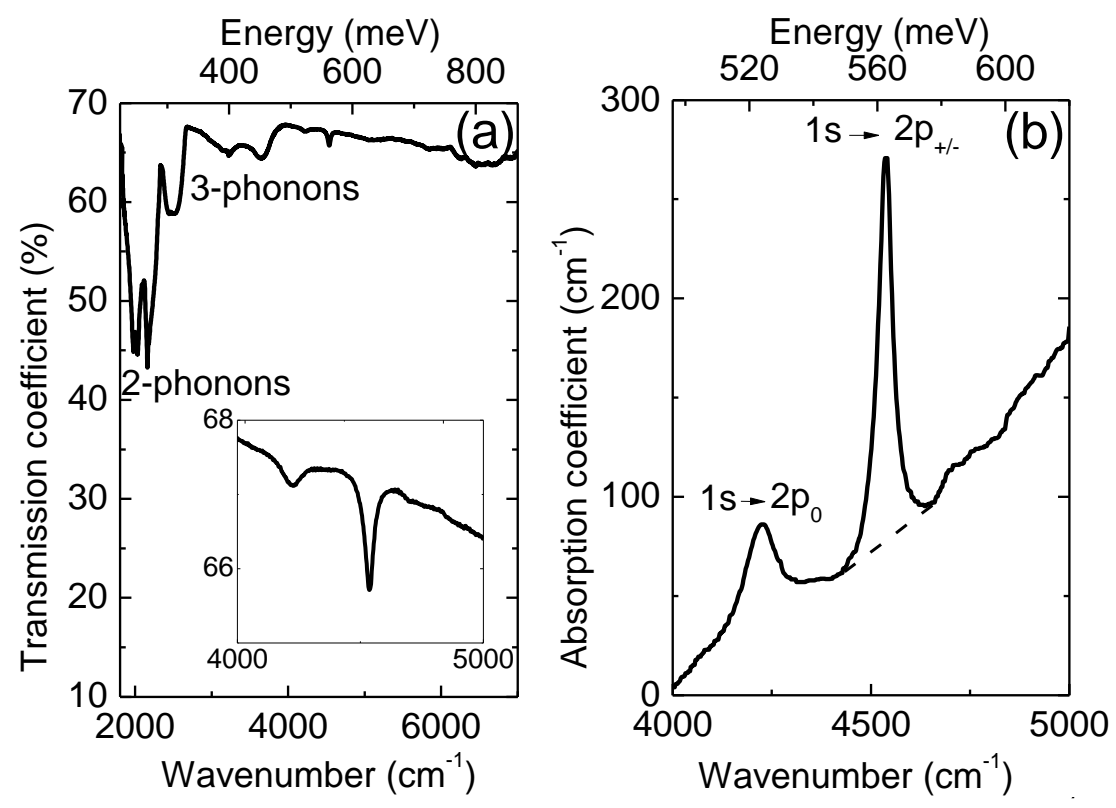
2 Absorption spectrum of sample D147 showing the electronic transitions of neutral phosphorus

3 in n-type diamond. A background line has been drawn in for the $4540 \mathrm{~cm}^{-1}$ band.

6 layers with different phosphorus contents. The photoionization continuous background has

7 been subtracted. The general trend is that the intensity of absorption increases when increasing 8 the phosphorus concentration in diamond. After background subtraction, the integrated

9 intensity, $\mathrm{I}_{\mathrm{A}}$, and the full width at half maximum (FWHM), $\Gamma$, of the $1 \mathrm{~s} \rightarrow 2 \mathrm{p}_{ \pm}$absorption peak 10 of the phosphorus-doped diamond layers at $10 \mathrm{~K}$, were extracted from a fit by using a Voigt 11 profile. The results are reported in Table1.

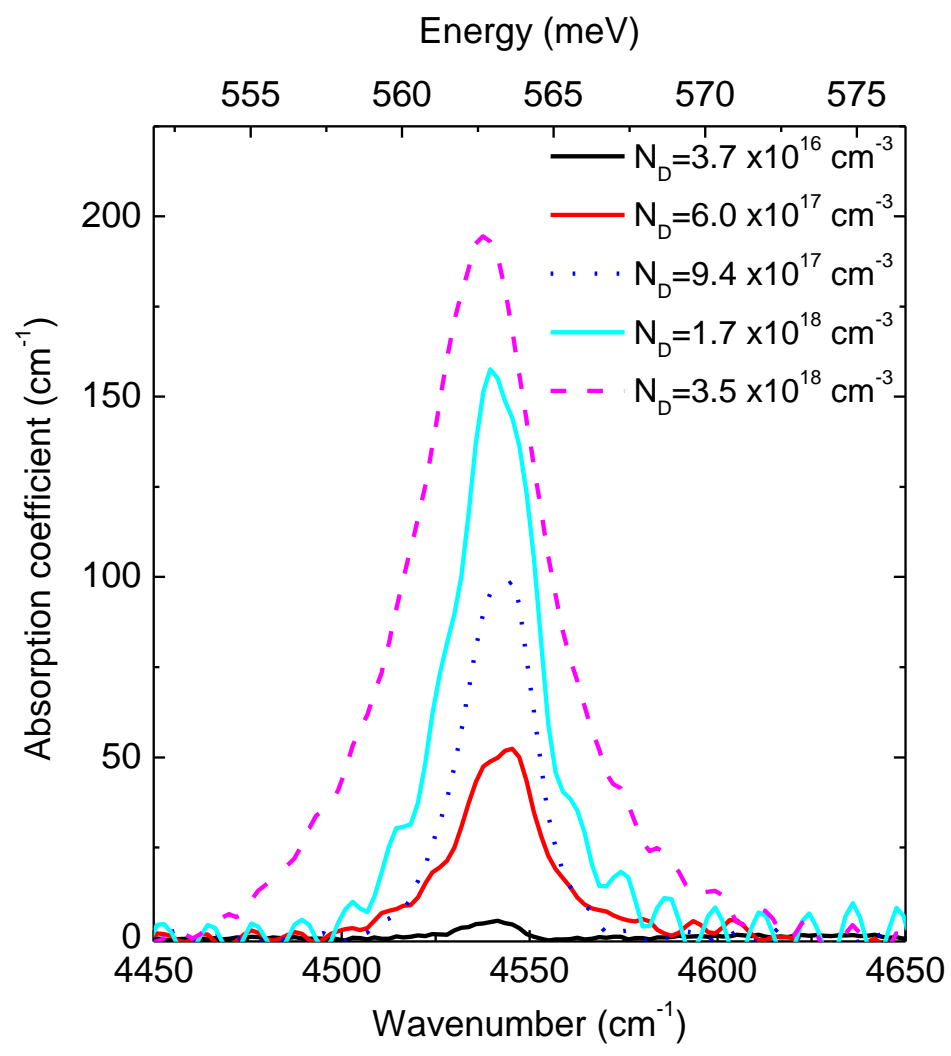


1 Fig. 2 (color on line): Absorption coefficient at the $1 \mathrm{~s} \rightarrow 2 \mathrm{p}_{ \pm}$electronic transition of neutral

2 phosphorus donors in diamond at $10 \mathrm{~K}$. It increases monotonically with the donor concentration

3 in the homoepitaxial layer.

4 The integrated intensity of the $1 \mathrm{~s} \rightarrow 2 \mathrm{p}_{ \pm}$absorption peak is plotted as a function of the net donor 5 concentration, $\mathrm{N}_{\mathrm{D}}-\mathrm{N}_{\mathrm{A}}$, in Figure 3. The net donor concentration corresponds to the part of 6 donors which are not compensated by residual acceptors (also mentioned as the 'uncompensated' donor concentration). We observe that the integrated intensity is proportional to $\mathrm{N}_{\mathrm{D}}-\mathrm{N}_{\mathrm{A}}$ over two decades. This important result is discussed in the following.

The $1 \mathrm{~s} \rightarrow 2 \mathrm{p}_{ \pm}$transition at $4540 \mathrm{~cm}^{-1}$ is attributed to neutral phosphorus donors. The intensity of this absorption line is then expected to be proportional to $\mathrm{N}_{\mathrm{D}}{ }^{0}$. At low temperatures, 11 donors are frozen. In other words, their excess electron remains bound to phosphorus, instead of feeding the conduction band with delocalized free electrons. In the absence of residual acceptors, all phosphorus atoms are expected to be neutral at low temperature. However, in the 14 presence of residual acceptors at a concentration $\mathrm{N}_{\mathrm{A}}<\mathrm{N}_{\mathrm{D}}$, part of donors give their excess electron to acceptors, resulting in the full ionization of the latter, $\mathrm{N}_{\mathrm{A}}=\mathrm{N}_{\mathrm{A}}{ }^{-}$. This describes the compensation phenomenon that occurs at thermodynamic equilibrium, whatever be the crystal temperature. In this process, a part of donors is also ionized $\left(\mathrm{N}_{\mathrm{D}}^{+}=\mathrm{N}_{\mathrm{A}}^{-}\right)$, and the neutral donor concentration is then reduced to $\mathrm{N}_{\mathrm{D}}{ }^{0}=\mathrm{N}_{\mathrm{D}}-\mathrm{N}_{\mathrm{A}}$. This explains why the amplitude of the absorption coefficient at the $1 \mathrm{~s} \rightarrow 2 \mathrm{p}_{ \pm}$energy is strictly proportional to the net donor density $\mathrm{N}_{\mathrm{D}}-\mathrm{N}_{\mathrm{A}}$ in the phosphorus-doped diamond samples (slope $=1.0$ in the $\operatorname{Ln}\left(\mathrm{I}_{\mathrm{A}}\right)$ vs $\operatorname{Ln}\left(\mathrm{N}_{\mathrm{D}}-\mathrm{N}_{\mathrm{A}}\right)$ plot). As a result,

21 the infrared spectroscopy of phosphorus in diamond has a strong potential to investigate the compensation phenomenon in n-type diamond.

Fig. 3 can be further considered as a calibration curve for future measurements of $\mathrm{N}_{\mathrm{D}^{-}}$

$24 \quad \mathrm{~N}_{\mathrm{A}}$ by infrared absorption. From it, we deduce the relationship (1) at $10 \mathrm{~K}$. For the case of 
1 experiments using liquid nitrogen cryostats, we also provide the relationship (2) measured at

$290 \mathrm{~K}$ using the same procedure.

3

$4 \quad N_{D}-N_{A}\left(\mathrm{~cm}^{-3}\right)=(2.7 \pm 0.2) \times 10^{14} \cdot I_{A}\left(\mathrm{~cm}^{-2}\right)$ at $10 \mathrm{~K}$

$5 \quad N_{D}-N_{A}\left(\mathrm{~cm}^{-3}\right)=(4.2 \pm 0.5) \times 10^{14} \cdot I_{A}\left(\mathrm{~cm}^{-2}\right)$ at $90 \mathrm{~K}$

6 Let us discuss the error bars of Fig. 3 and the uncertainties associated to equation (1) in

7 this paragraph. Considering $\mathrm{N}_{\mathrm{A}}=\mathrm{kN} \mathrm{N}_{\mathrm{D}}$, we deduce $\Delta \mathrm{N}_{\mathrm{A}} / \mathrm{N}_{\mathrm{A}}=\Delta \mathrm{k} / \mathrm{k}+\Delta \mathrm{N}_{\mathrm{D}} / \mathrm{N}_{\mathrm{D}}=30 \%$. The

8 uncertainty on $\mathrm{N}_{D}-\mathrm{N}_{\mathrm{A}}$ is then equal to $\Delta\left(\mathrm{N}_{\mathrm{D}}-\mathrm{N}_{\mathrm{A}}\right)=0.1 \mathrm{~N}_{\mathrm{D}}+0.3 \mathrm{~N}_{\mathrm{A}}$, formula used to plot the error

9 bars related to $\mathrm{N}_{\mathrm{D}}-\mathrm{N}_{\mathrm{A}}$ in Fig. 3. Concerning the absorption integrated intensity $\mathrm{I}_{\mathrm{A}}$, we consider

$10 \Delta \mathrm{I}_{\mathrm{A}} / \mathrm{I}_{\mathrm{A}}=20 \%$ including a relative uncertainty of $10 \%$ for the thickness of the epilayer. For

11 sample D169b, the uncertainty is larger due to a lower signal to noise ratio. Eq. 1 and the

12 associated uncertainty on the proportionality factor is the result of a least mean-square linear fit

13 of $\mathrm{I}_{\mathrm{A}}$ as a function of $\mathrm{N}_{\mathrm{D}}-\mathrm{N}_{\mathrm{A}}$ weighted by the error bars introduced in this paragraph. Finally,

14 the relative uncertainty on $\mathrm{N}_{\mathrm{D}}-\mathrm{N}_{\mathrm{A}}$ when using Eq. 1 is estimated at $27 \%$.

15 Note that the detection limit for the FTIR absorption of phosphorus in diamond is mainly driven

16 by the product of the concentration of absorbing impurities times film thickness. With our setup

17 and a typical integration time of 2 minutes, we experience a detection limit of approximately

$18 \quad \mathrm{~N}_{\mathrm{D}}-\mathrm{N}_{\mathrm{A}}\left(\mathrm{cm}^{-3}\right)=1 \times 10^{17} / \mathrm{d}(\mu \mathrm{m})$ 


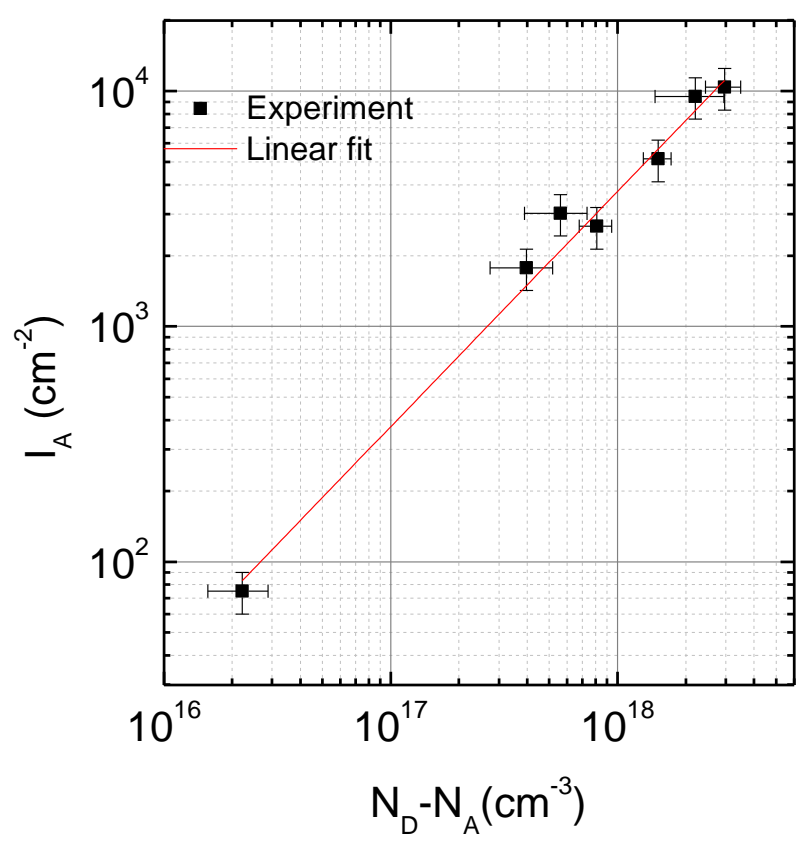

2 Fig. 3 : Integrated intensity of the $1 \mathrm{~s} \rightarrow 2 \mathrm{p}_{ \pm}$transition related absorption peak at $10 \mathrm{~K}$ versus the 3 neutral phosphorus donor concentration. D31 sample was excluded from Fig. 3 because of too 4 many SIMS craters ${ }^{3}$.

The linewidth (full width at half maximum) of the absorption peak is also worth investigating. In Table I, one can observe strong variations of the linewidth $\Gamma$ of the $1 \mathrm{~s} \rightarrow 2 \mathrm{p}_{ \pm}$ absorption peak in the series of samples, from $15 \mathrm{~cm}^{-1}$ to $64 \mathrm{~cm}^{-1}$. From our series of n-type diamond samples, we found $15 \mathrm{~cm}^{-1}$ for the narrowest peak. This is lower than the linewidth previously reported in ref [35] $\left(23 \mathrm{~cm}^{-1}\right)$, this is a good indication of the high quality of the layers. In Fig. 4, we have plotted the linewidth $\Gamma$ as a function of (a) $N_{D}$, (b) $N_{D}-N_{A}$ and (c) $N_{A}$. We observe that the linewidth almost follows a linear variation with $\mathrm{N}_{\mathrm{A}}$, whereas it is clearly not the case for $\mathrm{N}_{\mathrm{D}}$ or $\mathrm{N}_{\mathrm{D}}-\mathrm{N}_{\mathrm{A}}$.

\footnotetext{
${ }^{3}$ Concerning sample D31, it contains SIMS craters in the middle of the sample performed for a reproducibility experiments, so we decided to exclude the FTIR intensity from our study. Nevertheless, it is still an interesting sample which acceptor concentration is the highest of our series of samples. Note that a FTIR absorption spectrum of D31 can be found in [19] prior to the homogeneity study and confirms the large FWHM of the peak.
} 
In semiconductors, several effects are known to potentially broaden the electronic

2 absorption transitions of doping impurities: (i) the phonon lifetime broadening due to the

3 electron phonon interaction [36, 37] (ii) the overlap between impurity wavefunctions [38] ; (iii)

4 strain and inhomogeneities induced by defects and impurities [39,40] ; (iv) the presence of

5 random electric fields arising from ionized impurities $[41,42,43]$.

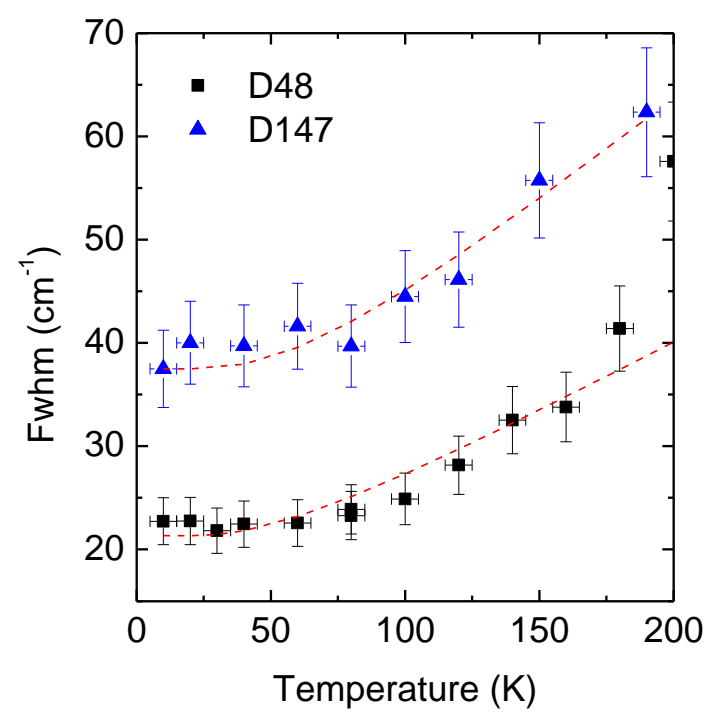

6

7 Fig. 4: Full width at half maximum of the $1 \mathrm{~s} \rightarrow 2 \mathrm{p}_{ \pm}$absorption peak as a function of temperature 8 for samples D48 and D147.

9 Starting with the phonon-induced broadening (i), it is expected to occur at high temperatures where the phonon population is significant. This is the reason why the linewidth

11 of the $1 \mathrm{~s} \rightarrow 2 \mathrm{p}_{ \pm}$absorption peak was measured as a function of temperature. To give examples,

12 it has been plotted in Fig. 4 for samples D48 and D147. We determine the characteristic 13 temperature $T_{c}$ above which electron-phonon interaction becomes predominant. We use the 14 phenomenological expression, proposed by Barrie and Nishikawa [44]:

$15 \Gamma=\frac{\Gamma_{0 K}}{1-\exp \left(-T_{C} / T\right)}$

16 where $\Gamma_{0 \mathrm{~K}}$ is the linewidth at $0 \mathrm{~K}$ and $\mathrm{T}_{\mathrm{c}}$ is the critical temperature. Setting these two parameters 17 as adjustment parameters in a chi-square minimization procedure, the phenomenological 
1 equation (2) appears to well describe the temperature dependence of the linewidth observed 2 experimentally. From the fit, we found $T_{c}=177 \mathrm{~K}$ for sample $\mathrm{D} 147$ and $\mathrm{T}_{\mathrm{c}}=151 \mathrm{~K}$ for sample 3 D48. These critical temperatures are much higher than $10 \mathrm{~K}$. As a result, the broadening due to 4 phonon interactions is negligible at $10 \mathrm{~K}$. In the next paragraphs, we propose to review the order of magnitudes of the other effects

6 (ii-iv) in the case of phosphorus-doped diamond assuming a 1s level associated with the

7 effective Bohr radius, $\mathrm{a}^{*}=1.4 \stackrel{\mathrm{o}}{\mathrm{A}}$, introduced previously. We insist on the fact that the ground 8 level of phosphorus donors in diamond cannot be described as a pure 1s level according to the 9 EMA theory. Still, the introduction of an effective Bohr radius makes possible to evaluate the 10 order of magnitudes of these effects in phosphorus doped diamond.

11 Concerning the donor wavefunction overlapping (ii), Baltensberger's calculations of the 1s, $122 \mathrm{~s}, 2 \mathrm{p}$ bands for a lattice of hydrogen-like impurities [45] show that the broadening of the 13 fundamental state becomes important when $r_{s} \approx 6 a^{*}$, with $\mathrm{a}^{*}$ the effective Bohr radius of the 14 bound carrier in a crystal with dielectric constant $\varepsilon . r_{s}$ is defined by $4 \pi r_{s}{ }^{3} / 3=1 / N_{D}$. Actually, 15 following the approach of Ref. [45] and using $\mathrm{a}^{*}=1.4 \AA$, the broadening of donor levels would only occur at concentrations above $4 \times 10^{20} \mathrm{P} . \mathrm{cm}^{-3}$. This is consistent with Fig. 5(a) and Fig. 5(b),

17 where the linewidth $\Gamma$ are plotted as a function of $N_{D}$ and $N_{D}-N_{A}$ respectively. No linear 18 variation of $\Gamma$ with $\mathrm{N}_{D}$ nor $\mathrm{N}_{\mathrm{D}}-\mathrm{N}_{\mathrm{A}}$ is observed. This evidences that $\mathrm{N}_{\mathrm{D}}$ is not the parameter 19 governing the broadening of the absorption peak in the investigated series of diamond epilayers 20 having $3.5 \times 10^{18}{\mathrm{P} . \mathrm{cm}^{-3}}$ at maximum. 

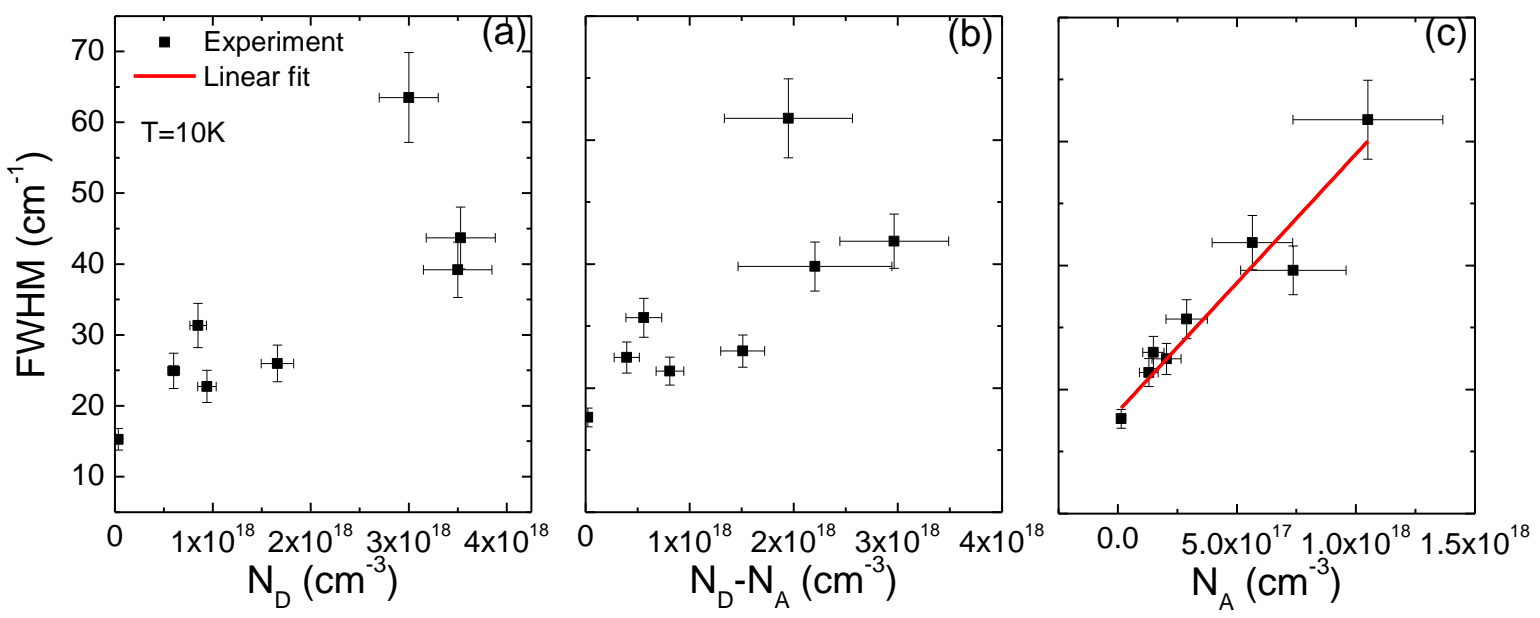

2 Fig. 5 : Full width at half maximum (linewidth $\Gamma$ ) at $10 \mathrm{~K}$ of the $1 \mathrm{~s} \rightarrow 2 \mathrm{p}_{ \pm}$absorption peak as a function of (a) the phosphorus donor concentration (b) the neutral phosphorus donor concentration (c) the acceptor concentration. All numerical values are given in Table I.

The broadening due to the random strain (iii) coming from the presence of defects and impurities (iii) is also unlikely. The impurity-induced broadening should be proportional to their total concentration in the crystal, which is not in agreement with our observations in Fig 5. Concerning dislocations, they give rise to internal strain that shifts the conduction band minima and hence broadens the excited states which follow them. This effect is expected to have a negligible contribution on the broadening of electronic transitions [40] at the low dislocation

11 densities of typically $10^{4-5}$ lines. $\mathrm{cm}^{-2}$ observed in homoepitaxial layers grown on HPHT substrates.

13 The ionized impurities (iv) are then likely to govern the linewidth of electronic transitions. As all acceptors are ionized at low temperature, the concentration of ionized impurities (positively and negatively charged ones) is $\mathrm{N}_{\mathrm{I}}=\mathrm{N}_{\mathrm{D}}{ }^{+}+\mathrm{N}_{\mathrm{A}}{ }^{-}=2 \mathrm{~N}_{\mathrm{A}}$. In other semiconductors like Ge [46], the presence of these charges is known to create an electric field distribution that perturbs the electronic states of the neutral impurities. In the assumption of a $1 \mathrm{~s}$ ground level, the 18 linewidth increases linearly with $\mathrm{N}_{\mathrm{I}}$ when the quadrupole interaction is dominant $[41,42,43]$. The absorption lineshapes are then symmetrical, as observed in Fig. 2. Such behaviour is also 
1 observed in our diamond samples (see Fig. 2). This effect of ionized impurities is also coherent 2 with our experimental results, namely an absorption linewidth which exhibits a linear 3 dependence on $\mathrm{N}_{\mathrm{A}}=\mathrm{N}_{\mathrm{I}} / 2$.

Fig. 5(c) shows the linewidth $\Gamma$ plotted as a function of $\mathrm{N}_{\mathrm{A}}$. We observe that the linewidth almost follows a linear variation with $\mathrm{N}_{\mathrm{A}}$. This result is consistent with a broadening governed by the presence of ionized impurities (iv), while all other effects (i)-(iii) appear negligible in our experimental conditions. Our work suggests that the electric field produced by ionized impurities widen the $1 \mathrm{~s} \rightarrow 2 \mathrm{p}_{ \pm}$transition of phosphorus donors.

As a perspective, the linewidth might provide a way to directly evaluate $\mathrm{N}_{\mathrm{A}}$, the compensator concentration, in phosphorus doped diamond. To that end, in Fig.5(c) is plotted 11 the result of a linear fit using a least mean-square procedure, each point weighted by its error $\operatorname{bar}\left(\Delta \mathrm{N}_{\mathrm{A}} / \mathrm{N}_{\mathrm{A}}=30 \%\right.$ and $\left.\Delta \Gamma / \Gamma=10 \%\right)$. From it, we deduce the following relationship at $10 \mathrm{~K}$ : $N_{A}\left(\mathrm{~cm}^{-3}\right)=(2.3 \pm 0.2) \times 10^{16} \times(\Gamma-15.3)\left(\mathrm{cm}^{-1}\right)$

14 Obviously, Eq. (3) is restricted to phosphorus-doped diamond with high acceptor concentrations $\mathrm{N}_{\mathrm{A}}>1.6 \times 10^{16} \mathrm{~cm}^{-3}$. For smaller acceptor concentrations, the minimum linewidth $16 \Gamma_{0}=15.3 \mathrm{~cm}^{-1}$ is reached. We also remind that Eq. 3 would be only valid for donor concentrations $17 \mathrm{~N}_{\mathrm{D}}<4.10^{20} \mathrm{~cm}^{-3}$, concentration at which wavefunction overlapping (ii) is expected to occur. In the severe limits mentioned above, the relative uncertainty on $\mathrm{N}_{\mathrm{A}}$ obtained by Eq.3 is estimated at $\Delta \mathrm{N}_{\mathrm{A}} / \mathrm{N}_{\mathrm{A}}=20 \%$.

Does $\Gamma_{0}$ represent the natural linewidth, also called the homogeneous broadening ? If yes, $\Gamma_{0}$ 21 would be an intrinsic value, independent of the sample. This would first deserve to be confirmed on other samples. Moreover, the value $\Gamma_{0}=15.3 \mathrm{~cm}^{-1}(1.9 \mathrm{meV})$ reached in sample D169b remains large compared to conventional semiconductors. For instance $\Gamma_{0} \lesssim 0.2 \mathrm{~cm}^{-1}$ in silicon

\footnotetext{
${ }^{4}$ Note that the FWHM of D169b is not limited by the spectral resolution of the apparatus. The lowest width that our setup is capable of resolving is $5 \mathrm{~cm}^{-1}$, at the resolution used in our study.
} 
1 is reported for most of dopants [15]. However, the situation in wide bandgap semiconductors

2 might be different, due to the deep character of their dopants. They are quite deep in diamond :

$3 \quad 0.6 \mathrm{eV}$ for phosphorus donors and $0.37 \mathrm{eV}$ for boron acceptors. The FWHM of the main

4 electronic absorption of boron acceptors at $2800 \mathrm{~cm}^{-1}$ in diamond was also found to reach a 14

$5 \mathrm{~cm}^{-1}$ minimum value in sample B01 of ref [13] which exhibits a boron concentration of [B]=

$610^{16} \mathrm{~cm}^{-3}$ and a very low compensation ratio (below $10^{-6}$ ). At this point, further research is

7 needed to answer this open question and to establish whether other effects contribute or not to

8 the minimum linewidth $\Gamma_{0}$ reached in this work ${ }^{5}$.

\section{E. How to evaluate the compensation ratio from infrared spectroscopy ?}

We have shown in section $\mathrm{C}$ that we can determine $\mathrm{N}_{\mathrm{D}}-\mathrm{N}_{\mathrm{A}}$ by infrared absorption with a relative uncertainty estimated at $27 \%$. In this section, we discuss different methods to determine the compensation ratio $\mathrm{k}$ with the help of electronic absorption spectroscopy of phosphorus donors in n-type diamond. We will pay attention to the relative uncertainty on $\mathrm{k}$. This is a rarely tackled issue, though combining different techniques can result in huge uncertainties.

If $\mathrm{N}_{\mathrm{D}}-\mathrm{N}_{\mathrm{A}}$ is measured by FTIR with Eq. (1) and $\mathrm{N}_{\mathrm{D}}$ is determined by another technique (CL or SIMS for instance), it is easy to show that $\Delta \mathrm{k} / \mathrm{k}=\left[\Delta\left(\mathrm{N}_{\mathrm{D}}-\mathrm{N}_{\mathrm{A}}\right) / \mathrm{N}_{\mathrm{D}}-\mathrm{N}_{\mathrm{A}}+\Delta \mathrm{N}_{\mathrm{D}} / \mathrm{N}_{\mathrm{D}}\right](1-\mathrm{k}) / \mathrm{k}$, based on the expression $\mathrm{N}_{\mathrm{D}}-\mathrm{N}_{\mathrm{A}}=(1-\mathrm{k}) \mathrm{N}_{\mathrm{D}}$. We obtain numerically: $\Delta \mathrm{k} / \mathrm{k}=0.37(1-\mathrm{k}) / \mathrm{k}$ when using the SIMS and FTIR uncertainties presented before. It is important to notice that $\Delta \mathrm{k} / \mathrm{k}$ is a decreasing function of $\mathrm{k}$. So the higher the compensation ratio, the lower the uncertainty on the

\footnotetext{
${ }^{5}$ The $2 p_{0}$ peak was unambiguously observed on several samples but not on the lowest concentration ones. A broadening of the $2 \mathrm{p}_{0}$ is also likely to occur but we were not able to evidence it.
} 
1 determination of $\mathrm{k}$. For instance, the uncertainty on $\mathrm{k}$ is only $4 \%$ for $\mathrm{k}=90 \%$. This method

2 should be preferred for highly compensated films $(\mathrm{k}>60 \%)$. using only FTIR. The compensation ratio $\mathrm{k}=\mathrm{N}_{\mathrm{A}} / \mathrm{N}_{\mathrm{D}}$ would be then assessed with an uncertainty $\Delta \mathrm{k} / \mathrm{k}=0.27-0.1 \mathrm{k}$, again a decreasing function of $\mathrm{k}$. In this case, $\Delta \mathrm{k} / \mathrm{k}$ ranges from $18 \%$ to $26 \%$ for $\mathrm{k}$ decreasing from $90 \%$ to $10 \%$. This method is more accurate than the first one for samples with low compensation level. In other cases it could be advantageous to combine $\mathrm{N}_{\mathrm{A}}$ determined by FTIR and $N_{D}$ known by another technique, SIMS here to be specific. This would give the uncertainty on $\mathrm{k}$ of $\Delta \mathrm{k} / \mathrm{k}=30 \%$.

\section{CONCLUSION}

The absorption coefficient spectra of phosphorus-doped diamond exhibit two peaks at $4220 \mathrm{~cm}^{-1}$ and $4540 \mathrm{~cm}^{-1}$ corresponding to the $1 \mathrm{~s} \rightarrow 2 \mathrm{p}_{0}$ and $1 \mathrm{~s} \rightarrow 2 \mathrm{p}_{+/-}$transitions of phosphorus donors in the neutral state of charge. The energy difference between them is consistent with the results of the Effective Mass Approximation theory applied here with updated electron effective masses. The main result of this work concerns the intensity of the $2 \mathrm{p}_{+/-}$related peak which is shown to be proportional to $\mathrm{N}_{\mathrm{D}}-\mathrm{N}_{\mathrm{A}}$, also called the net donor density. The integrated absorption cross-section of the transition was evaluated at $10 \mathrm{~K}$ and $90 \mathrm{~K}$, providing a direct way to evaluate the net donor density with a contact-less and non-destructive FTIR optical technique.

The linewidth of the peak is also shown to follow a linear dependence on $\mathrm{N}_{\mathrm{A}}$, which is consistent

21 with the presence of ionized impurities in the crystal. Specific cases have been identified where 22 infrared absorption - alone or in a combination with other techniques - could provide a 23 measurement of the compensation ratio. 
2 the compensation level in n-type diamond films. It offers a valuable complement to electrical measurements, particularly difficult to perform with highly resistive samples.

4

\section{ACKNOWLEDGEMENTS}

The DIAMONIX and DIAMONIX2 French research projects, approved by the competitiveness cluster of Aerospace Valley and funded by the Unique Interministerial Fund (FUI), are acknowledged for their financial support.

[1] S. Koizumi, K. Watanabe, M. Hasegawa, and H. Kanda, Ultra-violet emission from a diamond pn junction, Science 292, 1899 (2001).

[2] H. Umezawa, T. Saito, N. Tokuda, M. Ogura, S. G. Ri, H. Yoshikawa, and S. Shikata, Leakage current analysis of diamond Schottky barrier diode, Appl. Phys. Lett. 90, 073506 (2007).

[3] C. E. Nebel, B. Rezek, D. Shin, H. Uetsuka, and N. Yang, Diamond for bio-sensor applications, J. Phys. D 40, 6443 (2007).

[4] T. Makino, N. Tokuda, H. Kato, M. Ogura, H. Watanabe, S. G. Ri, S. Yamasaki, and H. Okushi, High-Efficiency Excitonic Emission with Deep-Ultraviolet Light from (001)Oriented Diamond p-i-n Junction, Jpn. J. Appl. Phys. 45, L1042 (2006).

[5] D. Takeuchi, T. Makino, H. Kato, M. Ogura, N. Tokuda, K. Oyama, T. Matsumoto, I. Hirabayashi, H. Okushi, and S. Yamasaki, Electron Emission from a Diamond (111) p-in+ Junction Diode with Negative Electron Affinity during Room Temperature Operation, Appl. Phys. Express 3, 041301 (2010).

[6] T. Makino, K. Yoshino, N. Sakai, K. Uchida, S. Koizumi, H. Kato, D. Takeuchi, M. Ogura, K. Oyama, T. Matsumoto, H. Okushi, and S. Yamasaki, Enhancement in emission 
efficiency of diamond deep-ultraviolet light emitting diode, Appl. Phys. Lett. 99, 061110 (2011).

[7] S. Koizumi, M. Kamo, Y. Sato, H. Ozaki and T. Inuzuka, Growth and characterization of phosphorous doped $\{111\}$ homoepitaxial diamond thin films, Appl. Phys. Lett. 71, 1065 (1997).

[8] H. Kato, S. Yamasaki, and H. Okushi, n-type doping of (001)-oriented single-crystalline diamond by phosphorus, Appl. Phys. Lett. 86, 222111 (2005).

[9] G. Frangieh, F. Jomard, M. A. Pinault and J. Barjon, Influence of tertiarybutylphosphine (TBP) addition on the CVD growth of diamond, Phys. Stat. Sol. A 206, 1996 (2009).

[10] H. Kato, J. Barjon, N. Habka, T. Matsumoto, D. Takeuchi, H. Okushi and S. Yamasaki, Energy level of compensator states in (001) phosphorus-doped diamond, Diamond Relat. Mater. 20, 1016 (2011).

[11] M-A.Pinault-Thaury, I. Stenger, F. Jomard, J. Chevallier, J. Barjon, A. Traore, D. Eon and J. Pernot, Electrical activity of (100) n-type diamond with full donor site incorporation of phosphorus, Phys. Stat. Sol. A 212, 2454 (2015)

[12] M. Katagiri, J. Isoya, S. Koizumi and H. Kanda, Lightly phosphorus-doped homoepitaxial diamond films grown by chemical vapor deposition, Appl. Phys. Lett. 85, 6365 (2004).

[13] J. Barjon, E. Chikoidze, F. Jomard, Y. Dumont, M. -A. Pinault-Thaury, R. Issaoui, O. Brinza, J. Achard, and F. Silva, Homoepitaxial boron-doped diamond with very low compensation, Phys. Stat. Sol. A 209, 1750 (2012)

[14] J. Barjon, P. Desfonds, M.-A. Pinault, T. Kociniewski, F. Jomard and J. Chevallier, Determination of the phosphorus content in diamond using cathodoluminescence spectroscopy, J. Appl. Phys. 101, 113701 (2007)

[15] B. Pajot, Optical absorption of impurities and defects in semiconducting crystals, Springer 
[16] A. T. Collins and A. W. S. Williams, The nature of the acceptor centre in semiconducting diamond, J. Phys. C 4, 1789 (1971)

[17] E. Gheeraert, S. Koizumi, T. Teraji, H. Kanda and M. Nesladek, Electronic states of phosphorus in diamond, Diam. Relat. Mat. 9, 948 (2000)

[18] T. Kociniewski, MA Pinault, J. Barjon, F. Jomard, J. and C. Saguy, MOCVD doping technology for phosphorus incorporation in diamond: Influence of the growth temperature on the electrical properties, Diamond Relat. Mater. 16, 815 (2007)

[19] T. Kociniewski, J. Barjon, M.-A. Pinault, F. Jomard, A. Lusson, D. Ballutaud, O. Gorochov, J.M. Laroche, E. Rzepka, J. Chevallier and C. Saguy, n-type CVD diamond doped with phosphorus using the MOCVD technology for dopant incorporation, Phys. Stat. Sol. (a) 203, $3136(2006)$

[20] M.-A. Pinault-Thaury, B. Berini, I. Stenger, E. Chikoidze, A. Lusson, F. Jomard, J. Chevallier, and J. Barjon, High fraction of substitutional phosphorus in a (100) diamond epilayer with low surface roughness, Appl. Phys. Lett. 100, 192109 (2012)

[21] M. Hasegawa, T. Teraji and S. Koizumi, Lattice location of phosphorus in n-type homoepitaxial diamond films grown by chemical-vapor deposition, Appl. Phys. Lett. 79, 3068 (2001)

[22] I. Stenger, M.-A. Pinault-Thaury, T. Kociniewski, A. Lusson, E. Chikoidze, F. Jomard, Y. Dumont, J. Chevallier and J. Barjon, Impurity-to-band activation energy in phosphorus doped diamond, J. Appl. Phys. 114, 073711 (2013)

[23] N. Naka, K. Fukai, Y. Handa, and I. Akimoto, Direct measurement via cyclotron resonance of the carrier effective masses in pristine diamond, Phys. Rev. B 88, 035205 (2013)

[24] J. P. Goss, R. Jones, M. I. Heggie, C. P. Ewels, P. R. Briddon and S. Oberg, Theory of hydrogen in diamond, Phys. Rev. B 65, 115207 (2002) 
[25] A. Mainwood and A. M. Stoneham, Stability of electronic states of the vacancy in diamond, J. Phys.: Condens. Matter 9, 2453 (1997).

[26] R. Jones, J. E. Lowther, and J. Goss, Limitations to n-type doping in diamond: The phosphorus-vacancy complex, Appl. Phys. Lett. 69, 2489 (1996).

[27] T. Miyazaki and S. Yamasaki, Ab initio energetics of phosphorus related complex defects in synthetic diamond, Physica B 376-377, 304 (2006).

[28] X. Zhou, G. D. Watkins, K. M. M. Rutledge, R. P. Messmer and S. Chawla, Hydrogenrelated defects in polycrystalline CVD diamond, Phys. Rev. B 54, 7881 (1996).

[29] C. Glover, M. E. Newton, P. M. Martineau, S. Quinn, and

D. J. Twitchen, Hydrogen Incorporation in Diamond: The Vacancy-Hydrogen Complex, Phys. Rev. Lett. 92, 135502 (2004).

[30] N. Mizuochi, H. Watanabe, H. Okushi, S. Yamasaki, J. Niitsuma, and T. Sekiguchi, Hydrogen-vacancy related defect in chemical vapor deposition homoepitaxial diamond films studied by electron paramagnetic resonance and cathodoluminescence, Appl. Phys. Lett. 88, $091912(2006)$.

[31] A. M. Zaitsev, Optical Properties of diamond, Springer, p69-124

[32] E. Gheeraert, N. Casanova, A. Tajani, A. Deneuville, E. Bustarret, J.A. Garrido, C.E. Nebel and M. Stutzmann, n-Type doping of diamond by sulfur and phosphorus, Diamond Relat. Mat. 11, $289(2002)$

[33] R.A. Faulkner, Higher Donor Excited States for Prolate-Spheroid Conduction Bands: A Reevaluation of Silicon and Germanium, Phys. Rev. 184, 713 (1969)

[34] B. Butorac, and A. Mainwood, Symmetry of the phosphorus donor in diamond from first principles, Phys. Rev. B 78, 235204 (2008)

[35] E. Gheeraert, N. Casanova, S. Koizumi, T. Teraji and H. Kanda, Low temperature excitation spectrum of phosphorus in diamond, Diamond Relat. Mat. 10, 444 (2001) 
[36] M. Lax and E. Burnstein, Broadening of Impurity Levels in Silicon, Phys. Rev. 100, 592 (1955)

[37] E. O. Kane, Phonon Broadening of Impurity Lines, Phys. Rev. 119, 40 (1960)

[38] B. I. Shklovskii and A. L. Efros, Electronic Properties of doped Semiconductors, Springer series in Solid-State Science, vol. 45, Springer, Berlin, p. 50

[39] M. Kogan and T. M. Lifshits, Photoelectric Spectroscopy - A New Method of Analysis of Impurities in Semiconductors, Phys. Stat. Sol. (a) 39, 11 (1977)

[40] C. Jagannath, Z. W. Grabowski, and A. K. Ramdas, Linewidths of the electronic excitation spectra of donors in silicon, Phys. Rev. B 23, 2082 (1981)

[41] S.M. Kogan and N. Van Lien, Stark broadening of spectral linesof hydrogenic impurities in lightly doped compensated semiconductors at low temperatures, Sov. Phys. Semicond. 15, $44(1981)$

[42] D. M. Larsen, Inhomogeneous Line Broadening in Donor Magneto-Optical Spectra Phys. Rev. B 8, 535 (1973)

[43] D. M. Larsen, Inhomogeneous broadening of the Lyman-series absorption of simple hydrogenic donors, Phys. Rev. B 13, 1681 (1976)

[44] R. Barrie and K. Nishikawa, Phonon broadening of impurity spectral lines: II. application to silicon, Can. J. Phys. 41, 1823 (1963)

[45] W. Baltensberger, Philos. Mag 44, 1355 (1953)

[46] K. M. Itoh, J. Muto, W. Walukiewicz, J. W. Beeman, E. E. Haller, Hyunjung Kim, A. J. Mayur, M. Dean Sciacca, A. K. Ramdas, R. Buczko, J. W. Farmer, and V. I. Ozhogin, Evidence for correlated hole distribution in neutron-transmutation-doped isotopically controlled germanium, Phys. Rev. B 53, 7797 (1996) 